\title{
Adaptation of the Basic Empathy Scale among a Portuguese sample of incarcerated juvenile offenders
}

\author{
Pedro Pechorro ${ }^{\mathrm{a} *}$, James V. Ray ${ }^{\mathrm{b}}$, Christopher P. Salas-Wright ${ }^{\mathrm{c}}$, João Maroco ${ }^{\mathrm{d}}$ and \\ Rui Abrunhosa Gonçalves ${ }^{\mathrm{a}}$ \\ ${ }^{a}$ School of Psychology, University of Minho, Braga, Portugal; ${ }^{b}$ Department of Criminal Justice, AQ2 \\ University of Texas at San Antonio, San Antonio, TX, USA; ' $S$ Chool of Social Work, The University \\ of Texas at Austin, Austin, TX, USA; ${ }^{d} I S P A$ - Instituto Universitário, Lisboa, Portugal
}

(Received 22 August 2014; accepted 2 March 2015)

The main aim of the present study was to examine the psychometric properties of the Basic Empathy Scale (BES) and of its adapted short version among a forensic sample of incarcerated male juvenile offenders $(N=221)$. The Portuguese validations of the BES and its adapted short version demonstrated good psychometric properties, namely in terms of the two-factor structure, internal consistency, convergent validity, discriminant validity, and concurrent validity that generally justifies its use among this population. Statistically significant associations were found with callousunemotional traits and social anxiety. Findings are discussed in terms of the use of the BES and its adapted short version with juvenile offenders.

Keywords: assessment; empathy; Basic Empathy Scale; juvenile delinquency; validation

\section{Introduction}

Empathy is defined, 'as the understanding and sharing in another's emotional state or $\mathrm{AQ}_{1}$ context' (Cohen \& Strayer, 1996, p. 523). Empathy is also often regarded as a multidimensional construct encompassing both affective and cognitive forms of empathy. The affective component of empathy refers to one's ability to experience the same emotions of others (i.e., emotion congruence; Bryant, 1982), whereas cognitive empathy refers to one's ability to recognize and understand the emotions of others (Hogan, 1969). Empathy and its distinct forms have been identified as important in moral development and interpersonal relationships and, thus, are positively associated with prosocial behaviors (Hoffman, 2008). Alternatively, a lack of empathy has been linked to antisocial behaviors and associated traits such as conduct disorder (CD; Cohen \& Strayer, 1996), offending (Jolliffe \& Farington, 2004), psychopathic traits (Muñoz, Qualter, \& Padgett, 2011), and drug use (Nguyen, Clark, \& Belgrave, 2011). That is, compared to individuals with empathy, those who lack empathy are more likely to continue engaging in antisocial and aggressive behaviors since they are unable to comprehend and experience the discomfort that their behaviors might inflict on another (Jolliffe \& Farrington, 2006). Thus, given its potential importance in the etiology of antisocial behavior and the treatment of juvenile offenders (e.g., Vachon, Lynam, \& Johnson, 2014), the development

*Corresponding author. Email: ppechorro@gmail.com 
and validation of measures designed to assess levels of empathy is essential for both research and practice.

\section{Development of the Basic Empathy Scale (BES)}

Several self-report measures have been developed to capture empathy including the Hogan Empathy Scale (Hogan, 1969), the Questionnaire Measure of Emotional Empathy (Mehrabian \& Epstein, 1972), and the Interpersonal Reactivity Index (IRI; Davis, 1980). However, Jolliffe and Farrington (2006) identified several shortcomings of these measures. First, they questioned the ability of these scales to adequately measure empathy highlighting that these measures tended to equate empathy with sympathy (a related but distinct trait) and an inability to capture the multidimensional nature of empathy (i.e., cognitive and affective forms). Second, validation of these measures were mainly done with university samples and, thus, may be inadequate for offending populations, particularly juveniles. That is, the homogeneous nature of university samples with regard to key variables (e.g., intelligence and social class) associated with both measurement and offending may have resulted in measures that fail to capture facets of empathy relevant to offending. In turn, Jolliffe and Farrington (2006) developed the BES to overcome these shortcomings of previously existing measures. In their initial study, they validated the BES among a sample of adolescent high school students in England and found strong support for both the factor structure and external validity of the BES. That is, they found support for a two-factor structure (cognitive and affective empathy) and found expected associations with external criteria including positive associations with the IRI and general personality traits of conscientiousness and agreeableness (general personality constructs that have been linked to psychopathy; Miller \& Lynam, 2003).

\section{Cross-cultural validations of the BES}

In addition to its original development and validation among an English sample of youths, several fairly recent studies have validated the BES across a wide array culturally distinct samples including Italian (Albiero, Matricardi, Speltri, \& Toso, 2009), French (D’Ambrosio, Olivier, Didon, \& Besche, 2009), Turkish (Topcu \& Erdur-Baker, 2012), Chinese (Geng, Xia, \& Qin, 2012), Spanish (Salas-Wright, Olate, \& Vaughn, 2012), and AQ4 Singaporean (Ang \& Goh, 2010) youth samples. With regard to its construct validity, the results from confirmatory factor analyses across these studies unanimously support the two-factor structure of the BES with each factor clearly representing the cognitive and affective forms of empathy and both the affective and cognitive scales showed adequate internal consistency across these samples ( $\alpha$ 's ranged from .73 to .85 and .66 to .81 , respectively).

Additionally, these cross-national studies found support for the external validity of the BES through its examination with several external criteria and convergence with existing measures of empathy. For instance, across these culturally distinct samples the BES scales correlated positively with other empathy scales including the Balanced Emotional Empathy Scale (Mehrabian, 1996) and the IRI (Albiero et al., 2009; D’Ambrosio et al., AQ5 2009). The BES also evinced positive associations with measures of prosocial behaviors (Albiero et al., 2009; Geng et al., 2012) and was negatively related to measures of internalizing disorders (e.g., alexithymia; D’Ambrosio et al., 2009) and emotional problems (Geng et al., 2012). However, there was less consistency with regard to the 
relationship between the BES scales and externalizing behaviors. For instance, Geng et al. (2012) found that the BES cognitive scale distinguished between youth with and without $\mathrm{CD}$ although the affective scale did not. Alternatively, Ang and Goh (2010) found the affective scale and not the cognitive scale to be negatively related to cyberbullying.

While these studies provide support for the use of the BES among culturally distinct groups, they are somewhat limited. For instance, despite the importance of empathy in juvenile offending (e.g., Jolliffe \& Farrington, 2007), none of these studies has validated the BES among a juvenile offender population. Salas-Wright et al. (2012) did examine AQ6 the criterion validity of the BES among a sample of high-risk youths involved in gangs. Their findings resulted in the development of a 7-item BES scale (3 affective and 4 cognitive items) and also found that youths who reported engaging in bullying and having a prior arrest had significantly lower cognitive empathy scores but no significant associations were found between affective empathy and such behaviors. Nonetheless, none of these studies have validated the BES among a sample of juveniles involved in the justice system. There are also several additional external criteria known to be associated with empathy which research has yet to examine in relation to the BES and its subscales.

\section{Empathy and psychopathy}

One construct that has conceptual overlap with empathy is psychopathy (e.g., Dadds, et al., 2009). Psychopathy is a multidimensional construct that includes affective (e.g., lack of empathy, guilt, and remorse), interpersonal (e.g., superficial charm and glibness), and antisocial lifestyle (e.g., impulsivity, risk taking) components (Hare \& Neumann, 2010). More recently, the extension of psychopathy to youths has highlighted the core affective components often referred to as callous-unemotional (CU) traits (Frick, Ray, Thornton, \& Kahn, 2013). Youths who are high on CU traits tend to engage in more severe and persistent offending due to a lack of concern for others (Frick et al., 2013). Given that low empathy is a core component of this construct, scores on measures CU traits would be expected to correlate negatively with empathy. However, past research suggests unique associations with the affective and cognitive components of empathy. That is, research tentatively finds CU traits to positively associate with cognitive empathy (Dadds et al., 2009), while a fairly consistent and robust negative association is found with affective empathy (Dadds et al., 2006; Kimonis, Frick, Fazekas, \& Loney, 2006; Muñoz, 2009) suggesting that youths with high CU traits understand but do not experience the emotions of others. However, despite its relevance to empathy, few studies have examined associations between the BES and measures of psychopathic traits among youths. Muñoz et al. (2011) examined the association between the BES and the inventory of callous-unemotional (ICU) traits (Kimonis et al., 2008) among a community sample of youths. They found negative correlations between the ICU and both the affective and cognitive scales of the BES. Nonetheless, more research is needed examining the association between psychopathic traits among youths and the BES, particularly among samples of justice involved youths.

\section{Empathy, aggression, and antisocial outcomes}

Another important set of criteria for validating measures of empathy include aggressive and antisocial behaviors. As previously mentioned, empathy is an important focus of treatment efforts with offenders (Vachon et al., 2014) because it has been considered a 
core etiological factor in such behaviors, particularly violent behaviors (Jolliffe \& Farrington, 2004). Given that the BES was developed with a particular emphasis on assessing empathy as it relates to antisocial behavior, such criteria are important for its validation. However, few studies examined associations with the BES and measures of antisocial behavior and aggression. Jolliffe and Farrington (2007) did find that among a community sample of youths those who self-reported any delinquency (e.g., marijuana use, theft, and violence) scored lower on empathy. It was also found that this association was especially relevant for males and tended to be stronger for affective empathy. A recent meta-analysis (van Langen, Wissink, van Vugt, van der Stouwe, \& Stams, 2014) examining the association between cognitive and affective empathy and offending found that cognitive, but not affective empathy, was related to offending. However, only one study with effect sizes reported for the BES was included in the analyses (van der Helm, Stams, van der Stel, van Langen, \& van der Laan, 2012) which had fairly equal effect sizes between affective empathy and delinquency and cognitive empathy and delinquency ( $d$ 's $=.49$ and .52 , respectively). Thus, few studies exist that have examined the relationship between empathy as measured by the BES and delinquency. Also, research has yet to examine associations between the BES and specific forms of antisocial behavior such as substance use.

Empathy, in general, has also been conceptually linked to aggression (Feshbach \& Feshbach, 1969) where empathy would be expected to show a negative relationship with aggression. However, this association is more complex when considering the multidimensional nature of empathy and distinct forms of aggression (i.e., reactive and proactive). Reactive aggression refers to aggressive response to perceived or actual threats and proactive aggression refers to more instrumental and unprovoked aggression (Crick \& Dodge, 1996). It has been suggested that cognitive empathy is more closely related to reactive aggression, whereas affective empathy is more closely related to proactive aggression (see Gordon, Dalton, Kolbert, Kanyongo, \& Crothers, 2014 for a review). More specifically, reactive aggression is less likely to be inhibited among those who are unable to recognize and understand another's emotions (i.e., cognitive empathy); while those who do not experience another's emotions (i.e., affective empathy), yet may or may not understand those emotions, are more capable of proactive forms of aggression. However, few studies have examined the BES scales in relation to distinct forms of aggression. Gordon et al. (2014) did examine this association among a sample of youths aged 9-11 years. They found that neither the cognitive nor affective scales of the BES were associated with proactive aggression while both showed negative associations with reactive aggression. Additional research is needed that examines the associations between the BES and aggression and antisocial behaviors.

\section{Empathy and anxiety}

Another trait whose relationship with empathy may help to provide both theoretical and practical import is anxiety. On the one hand, it has been suggested that those with high anxiety have less empathy than those with low anxiety due to a preoccupation with one's personal emotional state (Deardorff, Kendall, Finch, \& Sitarz, 1977). Alternatively, others have suggested that due to a preoccupation with how they are perceived by others, those high in anxiety have a heightened awareness regarding the emotional states of others (Tibi-Elhanany \& Shamay-Tsoory, 2011). However, few studies have examined the association between empathy and anxiety. Such research may be insightful, particularly 
given their shared overlap with constructs such as psychopathy and antisocial behavior. For instance, psychopaths are often characterized as having both low empathy and anxiety (Farrington, 2005). The few studies that have examined this association so far have not shown consistent support for either perspective. For instance, some studies have shown an inverse relationship between measures of empathy and anxiety (Berthoz, Wessa, Kidia, Wicker, \& Grezes, 2008; Deardorff et al., 1977) while others have found positive associations between the two constructs (Tibi-Elhanany \& Shamay-Tsoory, 2011). Additionally, when considering empathy as a multidimensional construct the relationship becomes even more complex. For instance, Tibi-Elhanany and ShamayTsoory (2011) found that a positive association existed between affective empathy and anxiety but not cognitive forms of empathy. Grynberg, Luminet, Corneille, Grèzes, and Berthoz (2010) found positive associations between affective empathy and anxiety and negative associations for cognitive empathy. In addition to the inconclusiveness the extant research, no studies exist that have examined how empathy as measured by the BES relates to anxiety, thus, more research is warranted in this domain.

\section{Current study}

The current study examines the psychometric properties of the relatively recently developed BES and extends its cross-cultural application among a Portuguese sample of incarcerated youthful offenders while attempting to address several of the other limitations of prior research. This study attempts to validate its use among a sample of detained juveniles using factor analysis to examine the internal structure of the BES among this unique sample. In addition to these aims, the current study also tests the psychometric properties of the recently developed short version of the BES (BES Adapted; Salas-Wright et al., 2012). It was predicted that: (1) the two-factor structure of the original BES and BES Adapted would be replicated among the current forensic sample of incarcerated youths; (2) the BES and BES Adapted would show discriminant validity with existing measures of psychopathy and aggression and their specific subscales, and convergent validity with a social anxiety measure; and that (3) the BES and BES Adapted scores would not be significantly associated with such variables as CD symptoms, alcohol abuse, and drug use.

\section{Method}

\section{Participants}

The sample was recruited from inmates of the eight nation-wide juvenile detention centers managed by the Portuguese Ministry of Justice. Two-hundred and twenty-one male participants $(N=221$; mean age $=16.75$ years; $\mathrm{SD}=1.41$ years; age range $=13-20$ years) agreed to voluntarily participate in the study. They were all detained by the court's decision. Incarceration into juvenile detention centers is the hardest measure a court can decide. Seven of the detention centers are considered low to medium security, and one is considered maximum security (exclusively used for youths tried as adults).

The participants were white Europeans (54.3\%), black Africans (20.5\%), mixed race South-Americans (18.6\%), and members of other ethnic minorities (6.8\%). Most of the participants came from an urban background $(92.8 \%)$. Their criminal onset (mean $=11.33$ years, $\mathrm{SD}=2.24$ years; range $=6-18$ years) and first criminal problems with the law had been early in their lives (mean $=12.84 ; \mathrm{SD}=1.97$; range $=7-18$ years), most were 
detained before they were 16 years old (mean $=15.46$ years, $\mathrm{SD}=1.31$ years; range $=$ 12-19 years), and had been convicted to an average of 21 months detention (mean = 20.67 months, SD $=6.69$ months). Most of them (87.6\%) were convicted of having committed serious and/or violent crimes (e.g., homicide, robbery, assault, rape).

\section{Measures}

The BES (Jolliffe \& Farrington, 2006) is a 20-item self-report measure designed to assess empathy in youths. The BES was developed as a concise and coherent scale with the aim of measuring two distinct factors: affective empathy (11 items) and cognitive empathy ( 9 items). Each item is scored on a 5 -point ordinal scale (from $1=$ strongly disagree to $5=$ strongly agree). Scores are calculated by reverse-scoring the positively worded items and then summing the items to obtain the total score and the factors scores. Higher scores indicate an increased presence of the associated characteristics. The BES Adapted (SalasWright et al., 2012) is an adapted short 7-item version of the BES that measures the same affective and cognitive dimensions. Internal consistency reliability statistics for the BES and BES Adapted will be given later in this paper.

Authorization to translate and validate a Portuguese version of the BES was obtained from the first author of the scale (Jolliffe \& Farrington, 2006). Appropriate procedures (e.g., avoiding item bias or differential item functioning) were followed during the translation and retroversion (Hambleton, Merenda, \& Spielberger, 2005). The initial translation from English into Portuguese was completed by the first and last authors of this article, who made sure that young people would be able to properly understand the meaning of the items. The questionnaire was then independently back-translated into English by a native English speaker with considerable professional experience in translating psychology-related scientific texts. The original and the back-translated items were compared for non-equivalence of meaning, and discrepancies were revised until no semantic differences were detected between the English version and the Portuguese version (i.e., the translated items had the same or very similar meanings as the original English items).

The Antisocial Process Screening Device - Self-report (APSD-SR; Frick \& Hare, 2001; Muñoz \& Frick, 2007) is a multidimensional 20-item measure designed to assess AQ7 AQ8 psychopathic traits in adolescents. It was modeled after the Psychopathy Checklist- AQ9 Revised (PCL-R; Hare, 2003). Each item is scored on a 3-point ordinal scale $(0=$ never, 1 AQ1 8 = sometimes, and $2=$ often $)$. The total score, as well as each dimension score, is obtained by adding the respective items. Some studies (e.g., Frick, O'Brien, Wootton, \& McBurnett, 1994) reported two main factors (CU and Impulsivity/Conduct problems), AQ11 while others (e.g., Frick, Barry, \& Bodin, 2000) reported three main factors: CU, AQ12 Narcissism, and Impulsivity. Higher scores are indicative of an increased presence of psychopathic traits. The Portuguese validation of the APSD-SR (Pechorro, Maroco, Poiares, \& Vieira, 2013) was used. The internal consistency for the current study, estimated by Cronbach's $\alpha$, was .81 .

The ICU traits (Essau, Sasagawa, \& Frick, 2006; Kimonis et al., 2008) is a 24-item AQ1z self-report scale designed to assess callous and unemotional traits in youths derived from the CU subscale of the APSD (Frick \& Hare, 2001). Each item is scored on a 4-point AQ14 scale $(0=$ not at all true, $1=$ somewhat true, $2=$ very true, and $3=$ definitely true $)$. Scores are calculated by reverse-scoring the positively worded items and then summing the items to obtain a total score. Using confirmatory factor analysis, it was possible to 
identify three independent factors, namely: Callousness (11 items), Uncaring (8 items), and Unemotional (5 items). Higher scores indicate an increased presence of the associated characteristics. The Portuguese validation of the ICU (Pechorro, Ray, Barroso, Maroco, \& Gonçalves, in press) was used. The internal consistency for the current study, estimated by Cronbach's $\alpha$, was .90 .

The Social Anxiety Scale for Adolescents (SAS-A; La Greca \& Lopez, 1998) is an 18 -item self-report scale designed to assess subjective experience of social anxiety in adolescents. Each item is rated on a 5-point scale $(0=$ not at all to $4=$ all the time $)$. Three distinct subscales have been identified: the Fear of Negative Evaluation subscale ( 8 items) reflects fears, concerns, or worries regarding negative evaluations from peers; the Social Avoidance and Distress - New subscale (6 items) reflects social avoidance and distress with new social situations or unfamiliar peers; the Social Avoidance and Distress General subscale (4 items) reflects more generalized or pervasive social distress, discomfort, and inhibition. Scores are obtained by summing the ratings for the items comprising each subscale. The Portuguese validation of the SAS-S (Pechorro, Silva, Maroco, \& Gonçalves, 2014) was used. Internal consistency for the present study, AQ1ฐ estimated by Cronbach's $\alpha$, was .91 .

The Reactive-Proactive Aggression Questionnaire (RPQ; Raine et al., 2006) is a selfreport measure that distinguishes between reactive and proactive aggression. The RPQ consists of 23 items rated on a 3 -point ordinal scale $(0=$ never, $1=$ sometimes, and $2=$ often). A total of 11 items assess reactive aggression (e.g., 'Reacted angrily when provoked by others') and 12 items assess proactive aggression (e.g., 'Hurt others to win a game'). Summed scores provide a measure of reactive or proactive aggression, as well as total aggression. Higher scores indicate higher levels of aggression. The RPQ is appropriate for use with youths in late adolescence and young adults. The Portuguese validation of the RPQ (Pechorro, Ray, Raine, Maroco, \& Gonçalves, 2015) was used. AQ1§ Internal consistency for the present study, estimated by Cronbach's $\alpha$, was .93 .

In addition to the measures described above, which were all used in the present study, a questionnaire was constructed to describe the socio-demographic characteristics of the participants. This questionnaire included variables such as participants' age, ethnic group, origin (rural vs. urban), level of schooling completed, drug use, alcohol abuse, age of criminal onset, age of first problem with the law, age of first detention, length of the detention, and types of crimes they were charged with. Diagnostic and statistical manual of mental disorders-5's (DSM-5's) CD (American Psychiatric Association, 2013) was AQ1 1 assessed using the official diagnostic criteria (i.e., the standard method described in the DSM-5).

\section{Procedures}

Authorization to assess youths was obtained from the General Directorate of Reintegration and Prison Services - Ministry of Justice (Direção-Geral de Reinserção e Serviços Prisionais - Ministério da Justiça). The detainees, from the eight existing Portuguese Juvenile Detention Centers that admit male youths, were informed about the nature of the study and asked to voluntarily participate. The participation rate was approximately $92 \%$. Not all young people agreed or were able to participate; reasons for this included refusal to participate $(5 \%)$, inability to participate due to not understanding the Portuguese language $(2 \%)$ and inability to participate due to security issues $(1 \%)$. Participants who were unwilling or unable to collaborate were excluded, so the final number of participants 
included in the present study was 221. The measures were administered by means of individual face-to-face interviews in an appropriate setting. It was stressed that there were no right or wrong answers and that for each item the youth should consider what he generally thinks or feels. Institutional files were also used to complement the information obtained (e.g., prior criminal activity and detentions). Some of the information (e.g., socio-demographic variables) was obtained from self-reports. The first author made the diagnosis of CD (APA, 2013).

The present study can be described as quantitative, non-experimental, and crosssectional (Bachman \& Schutt, 2003). The data were analyzed using SPSS v22 (IBM SPSS, 2013) and EQS 6.2 (Bentler \& Wu, 2008). The factor structure of the Portuguese language version was assessed with Confirmatory Factor Analysis (CFA) performed in EQS 6.2 (Bentler \& Wu, 2008; Byrne, 2006), with the robust estimation methods. Goodness-of-fit indices were calculated, including chi-square/degrees of freedom, Satorra-Bentler chi-square/degrees of freedom, comparative fit index (CFI), incremental fit index (IFI), root mean square error of approximation (RMSEA), and Akaike Information Criterion (AIC). A chi-square/degrees of freedom value $\leq 2$ is considered good and values $=1$ are considered very good (Maroco, 2014). A CFI $\geq .90$ and RMSEA $\leq .10$ indicate adequate fit, whereas a CFI $\geq .95$ and RMSEA $\leq .06$ indicate good model fit (Byrne, 2006). The incremental fit index, also known as Bollen's IFI, is relatively insensitive to sample size; values that exceed .90 are regarded as acceptable. Regarding the AIC, lower values indicate a better relative quality of the model.

The CFA was performed on the original scale items and only items with standardized loading above .45 were retained. Modification indexes were considered if necessary to check if any suggestion of model modification would significantly improve the measurement model. Polychoric correlations were used with robust methodologies to perform the CFA on the ordinal items because they provide more accurate estimates (Byrne, 2006). Pearson correlations were used to analyze associations between scale variables, Spearman correlations, and point-bisserial were used to analyze associations of scale variables with ordinal variables and nominal dichotomous variables (Leech, Barrett, \& Morgan, 2015).

\section{Results}

Our first step in examining the psychometric properties of a Portuguese version of the BES was to attempt to replicate, by means of CFA using the maximum likelihood (ML) Robust method, the different factor structures proposed for this instrument (e.g., Carré, Stefaniak, D'Ambrosio, Bensalah, \& Besche-Richard, 2013; Jolliffe \& Farrington, 2006; Salas-Wright et al., 2012). Shown in Table 1 are the goodness-of-fit indexes we obtained for the different models, namely: the one-factor model, the two-factor original model, the two-factor model adapted short version, and the three-factor model. We were able to find the strongest support in terms of goodness-of-fit indexes for the original two-factor model and for two-factor adapted short version of the BES. Because the BES and the BES Adapted have good fits, we decided to further analyze the psychometric properties of both measures.

Table 2 displays the item loadings for the two-factor original model and for the twofactor adapted short version structure estimated with the ML Robust method. All items had loadings well above .45 and, thus, none were removed from the model. 
Table 1. Goodness-of-fit indexes for the different models of the BES.

\begin{tabular}{lccccr}
\hline BES & S-B $\chi^{2}(\mathrm{df})$ & IFI & CFI & RMSEA & AIC \\
\hline 1-factor BES & $843.74(170)$ & .66 & .66 & $.13(.12-.14)$ & 503.74 \\
2-factor BES & $509.65(169)$ & .95 & .95 & $.09(.08-.10)$ & 171.65 \\
2-factor BES Adapted & $32.48(13)$ & .95 & .95 & $.08(.05-.12)$ & 6.48 \\
3-factor BES & $566.87(167)$ & .80 & .80 & $.10(.09-.11)$ & 232.87 \\
\hline
\end{tabular}

BES, Basic Empathy Scale; $\chi^{2}$, chi-square; S-B $\chi^{2}$, Satorra-Bentler chi-square; df, degrees of freedom; IFI, Incremental Fit Index; CFI, Comparative Fit Index; RMSEA $(90 \% \mathrm{CI})$, root mean square error of approximation ( $90 \%$ confidence interval); AIC, Akaike information criterion; ML, maximum likelihood; 2-factor Adapted, 2factor adapted short version.

Table 2. BES and BES Adapted item loadings for the confirmatory two-factor inter-correlated robust structure.

\section{Items}

Factor 1 Factor 2

BES affective

1. My friend's emotions don't affect me much.

2. After being with a friend who is sad about something I usually feel [...]. $\quad .73$

4. I get frightened when I watch characters in a good scary movie.

5. I get caught up in other people's feelings easily. 63

7. I don't become sad when I see other people crying. $\quad .78$

8. Other people's feelings don't bother me at all.

11. I often become sad when watching sad things on TV or in films. $\quad .50$

13. Seeing a person who has been angered has no effect on my feelings. $\quad .51$

15. I tend to feel scared when I am with friends who are afraid. .53

17. I often get swept up in my friend's feelings. $\quad .64$

18. My friend's unhappiness doesn't make me feel anything. $\quad .68$

BES cognitive

3. I can understand my friend's happiness when she/he does well at [...].

6. I find it hard to know when my friends are frightened.

9. When someone is feeling 'down,' I can usually understand how [...].

10. I can usually workout when my friends are scared. $\quad .79$

12. I can often understand how people are feeling even before they [...].

14. I can usually workout when people are cheerful. $\quad .75$

16. I can usually realize quickly when a friend is angry. $\quad .84$

19. I am not usually aware of my friend's feelings.

20. I have trouble figuring out when my friends are happy. $\quad .73$

BES Adapted affective

1. After being with a friend who is sad about something I usually feel [...]. $\quad .67$

2. I get caught up in other people's feelings easily. $\quad .70$

3. I often get swept up in my friend's feelings.

BES Adapted cognitive

4. When someone is feeling 'down,' I can usually understand how [...]. 71

5. I can usually figure out when my friends are scared. $\quad .67$

6. I can often understand how people are feeling even before they [...]. 76

\begin{tabular}{ll}
7. & I can usually figure out when people are cheerful. \\
\hline
\end{tabular}

BES, Basic Empathy Scale; BES Adapted, BES Adapted short version. 
Table 3 presents the correlations between the BES total (and its dimensions) and the BES Adapted total (and its dimensions). As expected, the correlations of the two measures and its dimensions were moderate to strong and statistically significant.

We also calculated Cronbach's $\alpha$, mean inter-item correlations, and corrected itemtotal correlation range for the BES and the BES Adapted (Table 4). In terms of the internal consistency of the two measures, it is worth pointing out that these values can be considered quite good.

The discriminant validity of the BES/BES Adapted with the APSD-SR, the ICU, and the RPQ revealed mostly the expected low or negative correlations, while the convergent validity with the SAS-A revealed the expected statistically significant moderate positive correlations (Table 5). The concurrent validity of the BES/BES Adapted with other variables, namely with DSM-5's CD symptoms (scored as a scale), and cannabis use revealed statistically significant negative low correlations, but no significant correlations were found with alcohol use and cocaine/heroin use (all coded as 5-point ordinal scales) (Table 5). Regarding the DSM-5 CD diagnostic, a very high prevalence rate of $94.1 \%$ was found in our sample.

\section{Discussion}

The primary aim of the present study was to assess the psychometric properties of the BES and BES Adapted among a sample of incarcerated Portuguese juvenile delinquents. Evidence obtained in our study shows that the original two-factor model is the most acceptable one for the Portuguese version of the BES, whereas one-factor and three-factor models did not fit our data well. Other studies (e.g., Albiero et al., 2009; Jolliffe \& Farington, 2004) have found supporting evidences for the two-dimensional nature of empathy as a good option, and this seems to apply to the current sample. Regarding the BES Adapted, the present study confirms that the two-factor model is very applicable. Salas-Wright et al. (2012) also found supporting evidence for the two-factor structure of the BES Adapted among high-risk and gang-involved adolescents and young adults, and this seems to apply also to the Portuguese incarcerated adolescents. This leads us to consider that our first hypothesis was supported.

The correlations between the BES total and its dimensions showed mostly moderate to high statistically significant positive associations. The same pattern of associations was observable regarding the BES Adapted and its dimensions, and regarding the associations

Table 3. BES and BES Adapted correlations matrix.

\begin{tabular}{lcccccc}
\hline & BES & BES A & BES C & BES Ad & BES Ad A & BES Ad C \\
\hline BES & 1 & & & & & \\
BES A & $.88^{* * *}$ & 1 & & & & \\
BES C & $.82^{* * *}$ & $.49^{* * *}$ & 1 & & & \\
BES Ad & $.92^{* * *}$ & $.76^{* * *}$ & $.85^{* * *}$ & 1 & & \\
BES Ad A & $.79^{* * *}$ & $.86^{* * *}$ & $.48^{* * *}$ & $.82^{* * *}$ & 1 & 1 \\
BES Ad C & $.77^{* * *}$ & $.46^{* * *}$ & $.93^{* * *}$ & $.88^{* * *}$ & $.44^{* * *}$ & 1 \\
\hline
\end{tabular}

BES, Basic Empathy Scale; BES A, BES Affective dimension; BES C, BES Cognitive dimension; BES Ad, BES Adapted short version; BES Ad A, BES Adapted Affective dimension; BES Ad C, BES Adapted Cognitive dimension.

***significant at the .001 level. 
Table 4. BES and BES Adapted Cronbach's alphas, mean inter-item correlations, and corrected itemtotal correlation range.

\begin{tabular}{lrccc}
\hline & \multicolumn{1}{c}{ SR } & $\alpha$ & MIIC & CITCR \\
\hline BES total & $20-100$ & .91 & .32 & $.21-.68$ \\
BES Affective dimension & $11-55$ & .87 & .37 & $.25-.70$ \\
BES Cognitive dimension & $9-45$ & .90 & .50 & $.56-.76$ \\
BES Adapted total & $7-35$ & .81 & .37 & $.45-.59$ \\
BES Adapted Affective dimension & $3-15$ & .74 & .49 & $.51-.61$ \\
BES Adapted Cognitive dimension & $4-20$ & .80 & .50 & $.59-.65$ \\
\hline
\end{tabular}

$\mathrm{BES}=$ Basic Empathy Scale; BES Adapted = BES Adapted short version; $\mathrm{SR}=$ Score range; Alpha = Cronbach's $\alpha$; MIIC $=$ Mean inter-item correlation; CITCR $=$ Corrected item-total correlation range.

*** significant at the .001 level

Table 5. Correlations of BES and BES Adapted with APSD-SR, ICU, RPQ, SAS-A, CD symptoms, alcohol abuse, cannabis use, and cocaine/heroin use.

\begin{tabular}{|c|c|c|c|}
\hline & $\begin{array}{c}\text { BES/BES Adapted } \\
\text { total }\end{array}$ & $\begin{array}{c}\text { BES/BES Adapted } \\
\text { Affective }\end{array}$ & $\begin{array}{l}\text { BES/BES Adapted } \\
\text { Cognitive }\end{array}$ \\
\hline APSD-SR total & $-.13 * /-.11^{\mathrm{ns}}$ & $-.17 * * /-.11^{\mathrm{ns}}$ & $-.02^{\mathrm{ns}} /-.08^{\mathrm{ns}}$ \\
\hline $\begin{array}{l}\text { APSD-SR } \\
\text { Impulsivity }\end{array}$ & $.11^{\mathrm{ns}} / .11^{\mathrm{ns}}$ & $.08^{\mathrm{ns}} / .12^{\mathrm{ns}}$ & $.10^{\mathrm{ns}} / .07^{\mathrm{ns}}$ \\
\hline $\begin{array}{l}\text { APSD-SR } \\
\text { Narcissism }\end{array}$ & $.05^{\mathrm{ns}} / .04^{\mathrm{ns}}$ & $-.02^{\mathrm{ns}} / .01^{\mathrm{ns}}$ & $.08^{\mathrm{ns}} / .06^{\mathrm{ns}}$ \\
\hline APSD-SR CU & $-.50 * * * /-.44 * * *$ & $-.46^{* * *} /-.38^{* * *}$ & $-.40^{* * *} /-.37 * * *$ \\
\hline ICU total & $-.41 * * * /-.38 * * *$ & $-.43 * * * /-.31 * * *$ & $-.28 * * * /-.33 * * *$ \\
\hline ICU Callousness & $-.15 * /-.13 *$ & $-.23 * * * /-.14 *$ & $-.02^{\mathrm{ns}} /-.08^{\mathrm{ns}}$ \\
\hline ICU Uncaring & $-.45 * * * /-.42 * * *$ & $-.40^{* * *} /-.30^{* * *}$ & $-.39 * * * /-.40 * * *$ \\
\hline ICU Unemotional & $-.47 * * * /-.43 * * *$ & $-.44 * * * /-.33 * * *$ & $-.38 * * * /-.39 * * *$ \\
\hline RPQ total & $.08^{\mathrm{ns}} / .08^{\mathrm{ns}}$ & $.00^{\mathrm{ns}} / .05^{\mathrm{ns}}$ & $.12^{\mathrm{ns}} / .09^{\mathrm{ns}}$ \\
\hline RPQ Reactive & $.12^{\mathrm{ns}} / .13^{\mathrm{ns}}$ & $.07^{\mathrm{ns}} / .10^{\mathrm{ns}}$ & $.13^{\mathrm{ns}} / .11^{\mathrm{ns}}$ \\
\hline RPQ Proactive & $.03^{\mathrm{ns}} / .4^{\mathrm{ns}}$ & $-.06^{\mathrm{ns}} / .00^{\mathrm{ns}}$ & $.10^{\mathrm{ns}} / .06^{\mathrm{ns}}$ \\
\hline SAS-A total & $.39 * * * / .31 * * *$ & $.43 * * * / .35 * * *$ & $.19^{* * / .19^{* *}}$ \\
\hline SAS-A General & $.23 * * * / .17 *$ & $.31 * * * / .22 * * *$ & $.05^{\mathrm{ns}} / .08^{\mathrm{ns}}$ \\
\hline SAS-A New & $.26 * * * / .17 *$ & $.30 * * * / .21 * *$ & $.11^{\mathrm{ns}} / .09^{\mathrm{ns}}$ \\
\hline SAS-A FNE & $.39 * * * / .33 * * *$ & $.40^{* * *} / .35^{* * *}$ & $23 * * * / .22 * *$ \\
\hline CD symptoms & $-.08^{\mathrm{ns}} /-.10^{\mathrm{ns}}$ & $-.17^{* *} /-.13^{n s}$ & $.05^{\mathrm{ns}} /-.05^{\mathrm{ns}}$ \\
\hline Alcohol & $-.02^{\mathrm{ns}} /-.03^{\mathrm{ns}}$ & $-.06^{\mathrm{ns}} /-.00^{\mathrm{ns}}$ & $.01^{\mathrm{ns} /}-.05^{\mathrm{ns}}$ \\
\hline Cannabis & $-.08^{\mathrm{ns}} /-.08^{\mathrm{ns}}$ & $-.14 * /-.06^{\mathrm{ns}}$ & $.01^{\mathrm{ns}} /-.07^{\mathrm{ns}}$ \\
\hline Cocaine/heroin & $-.02^{\mathrm{ns} / .03^{\mathrm{ns}}}$ & $-.05^{\mathrm{ns}} /-.01^{\mathrm{ns}}$ & $.02^{\mathrm{ns}} / .06^{\mathrm{ns}}$ \\
\hline
\end{tabular}

BES = Basic Empathy Scale; BES Adapted = BES Adapted short version; APSD-SR = Antisocial Process Screening Device - Self-Report; APSD-SR Impulsivity = Impulsivity dimension; APSD-SR Narcissism = Narcissism dimension; APSD-SR Callous-Unemotional = Callous-Unemotional dimension; ICU = Inventory of Callous-Unemotional Traits; ICU Callousness = Callousness dimension; ICU Uncaring = Uncaring dimension; ICU Unemotional = Unemotional dimension; RPQ = Reactive-Proactive Aggression Questionnaire; RPQ Reactive $=$ Reactive dimension; RPQ Proactive $=$ Proactive dimension; SAS-A $=$ Social Anxiety Scale for Adolescents; SAS-A General $=$ General dimension; SAS-S New = New dimension; SAS-A FNE $=$ Fear of Negative Evaluation dimension; CD symptoms = DSM-5 Conduct Disorder symptoms.

$* * *$ significant at the .001 level; **significant at the .01 level; *significant at the .05 level; ns = non-significant. 
between the BES Adapted (and its dimensions) and the original BES (and its dimensions). These values were similar to the ones found by other studies (e.g., Albiero et al., 2009; Jolliffe \& Farington, 2004; Salas-Wright et al., 2012).

Analyses of the internal consistency revealed that the BES and its two dimensions presented good or very good values (Kaplan \& Saccuzzo, 2009). Jolliffe and Farington (2004) found similar results. Regarding the BES Adapted, the analysis of the internal consistency revealed a somewhat lower value for the Affective dimension but still well above the recommended value of .70 (Kaplan \& Saccuzzo, 2009). Salas-Wright et al. (2012) also found similar results. In terms of the mean inter-item correlations of the BES and BES Adapted no problems were identified because the total scales and its dimensions were all within the recommended range of .15-.50 (Clark \& Watson, 1995; Domino \& Domino, 2006). The corrected item-total correlation range of the BES and its dimension and BES Adapted and its dimensions were all above the minimum recommended value of .20 (Kaplan \& Saccuzzo, 2009).

The discriminant validity of the BES/BES Adapted and its dimensions with the measures of psychopathic traits (i.e., APSD-SR and the ICU) revealed findings consistent with prior research (e.g., Muñoz et al., 2011). That is, the BES showed consistent negative correlations with the APSD CU scale and the ICU and its subscales. Additionally, the Callousness subscale of the ICU was unrelated to the BES Cognitive domain which is consistent with the notion that $\mathrm{CU}$ youths understand emotions of others (Dadds et al., 2009), but do not experience or share those emotions. Other aspects of psychopathy construct (i.e., behavioral and interpersonal components) as measured by the APSD, however, were unrelated to the BES and its subscales which is consistent with prior research examining the relationship between empathy and impulsivity (Jolliffe \& Farrington, 2006; Pardini, Lochman, \& Frick, 2003). The RPQ and its subscales, on the other hand, were unrelated to the BES and its subscales. This finding is consistent with a recent meta-analysis that identified very weak associations between empathy and aggression (Vachon et al., 2014). As expected, convergent validity with the SAS-A revealed mostly positive moderate correlations (American Psychological Association, 1999; Kaplan \& Saccuzzo, 2009) that were consistent with the studies that found positive associations between the two constructs (e.g., Tibi-Elhanany \& Shamay-Tsoory, 2011). Therefore, the second hypothesis that was previously set was confirmed.

With the exception of the BES Affective dimension, the BES/BES Adapted was unrelated to DSM-5 CD symptoms (American Psychiatric Association, 2013). The BES Affective dimensions showed a small negative correlation with $\mathrm{CD}$. The very high prevalence rates of $\mathrm{CD}$ among the current sample (94.1\%) were in the higher range of what is typical of some forensic samples (Sevecke \& Kosson, 2010), which may explain AQ18 the lack of association between the BES and CD due to low variability. The correlations of the BES/BES Adapted and its dimensions with alcohol use, cannabis use, and cocaine/ heroin use revealed mostly non-significant associations. Therefore, also in this final case, we consider that the third hypothesis that was previously set was confirmed.

Overall, we were able to demonstrate some appropriate psychometric properties that justify the future use of the BES and of the BES Adapted. However, some caution is advised since the Portuguese validation of these important instruments is still ongoing. In terms of the limitations of our study, we must mention that further psychometric procedures are needed and must be done in the near future (e.g., cross-validation using different samples, test-retest reliability). Another important limitation was the relatively small sample size, which is an important issue especially given that CFA was used (both 
Type I and II errors are much more likely with small samples, and this concern is elevated when the data are skewed). A final limitation of the current study was the fact that we did not control for intelligence and socio-economic status (Jolliffe \& Farrington, 2004). Thus, future cross-cultural studies of empathy and its relationship with external criteria should account for it, particularly offending, in order to determine the predictive utility of the BES.

To our knowledge, this is the first study attempting to investigate the psychometric properties of the BES and of the BES Adapted among a Portuguese sample of incarcerated juvenile delinquents. We extend the usefulness of the BES by examining its validity among a culturally distinct sample of Portuguese juvenile offenders. Thus, the use of the BES in juvenile justice settings is warranted based on the findings of the current study. Importantly, we also identify the BES Adapted scale as a promising measure of empathy that may be useful to both researchers and clinicians when efficiency is a concern. Considering the enormous costs that serious and violent juvenile delinquents create in terms of their crimes and collateral effects on victims and society as a whole, we hope that our study may guide future research/use of these instruments, contribute to the betterment of treatment programs of detained serious and violent juvenile offenders in Portugal, and promote future research and a more generalized use of the BES in Portuguese-speaking countries.

\section{Acknowledgments}

We wish to thank the following Portuguese juvenile detention centers for their collaboration: Bela Vista, Mondego, Navarro de Paiva, Olivais, Padre António Oliveira, Santo António, Santa Clara, Prisão-Escola de Leiria.

\section{Disclosure statement}

No potential conflict of interest was reported by the authors.

\section{Funding}

This research was supported by the Portuguese Foundation for Science and Technology (FCT) with co-financing of the European Social Fund - POPH/FSE [grant number SFRH/BPD/86666/2012].

\section{References}

Albiero, P., Matricardi, G., Speltri, D., \& Toso, D. (2009). The assessment of empathy in AQ2Q adolescence: A contribution to the Italian validation of the "Basic Empathy Scale". Journal of Adolescence 32, 393-408. doi:10.1016/j.adolescence.2008.01.001

American Psychiatric Association. (2013). Diagnostic and statistical manual of mental disorders (5th ed.). Washington, DC: Author.

American Psychological Association. (1999). Standards for educational and psychological tests. Washington, DC: Author.

Ang, R. P., \& Goh, D. H. (2010). Cyberbullying among adolescents: The role of affective and cognitive empathy, and gender. Child Psychiatry \& Human Development, 41, 387-397. doi:10.1007/s10578-010-0176-3

Bachman, R., \& Schutt, R. (2003). The practice of research in criminology and criminal justice (2nd ed.). London: Sage.

Bentler, P., \& Wu, E. (2008). EQS for Windows user's guide. Encino, CA: Multivariate Software.

Berthoz, S., Wessa, M., Kedia, G., Wicker, B., \& Grezes, J. (2008). Cross-cultural validation of the empathy quotient in a French-speaking sample. Canadian Journal of Psychiatry/Revue Canadienne de Psychiatrie, 53, 469-477. 
Bryant, B. K. (1982). An index of empathy for children and adolescents. Child Development, 53, 413-425. doi:10.2307/1128984

Byrne, B. (2006). Structural equation modeling with EQS: Basic concepts, applications, and programming. Mahwah, NJ: Lawrence Erlbaum Associates.

Carré, A., Stefaniak, N., D’Ambrosio, F., Bensalah, L., \& Besche-Richard, C. (2013). The Basic Empathy Scale in adults (BES-A): Factor structure of a revised form. Psychological Assessment, 25, 679-691. doi:10.1037/a0032297

Clark, L., \& Watson, D. (1995). Constructing validity: Basic issues in objective scale development. Psychological Assessment, 7, 309-319. doi:10.1037/1040-3590.7.3.309

Cohen, D., \& Strayer, J. (1996). Empathy in conduct-disordered and comparison youth. Developmental Psychology, 32, 988-998. doi:10.1037/0012-1649.32.6.988

Crick, N. R., \& Dodge, K. A. (1996). Social information-processing mechanisms in reactive and proactive aggression. Child Development, 67, 993-1002. doi:10.2307/1131875

Dadds, M. R., Perry, Y., Hawes, D. J., Merz, S., Riddell, A. C., Haines, D. J., ... Abeygunawardane, A. I. (2006). Attention to the eyes and fear-recognition deficits in child psychopathy. The British Journal of Psychiatry, 189, 280-281. doi:10.1192/bjp.bp.105.018150

Dadds, M. R., Hawes, D. J., Frost, A. D., Vassallo, S., Bunn, P., Hunter, K., \& Merz, S. (2009). Learning to 'talk the talk': The relationship of psychopathic traits to deficits in empathy across childhood. Journal of Child Psychology and Psychiatry, 50, 599-606. doi:10.1111/j.14697610.2008.02058.x

D’Ambrosio, F., Olivier, M., Didon, D., \& Besche, C. (2009). The Basic Empathy Scale: A French validation of a measure of empathy in youth. Personality and Individual Differences, 46, 160165. doi:10.1016/j.paid.2008.09.020

Davis, M. A. (1980). A multidimensional approach to individual differences in empathy. JSAS Catalog of Selected Documents, 10, 85.

Deardorff, P. A., Kendall, P. C., Finch Jr, A. J., \& Sitarz, A. M. (1977). Empathy, locus of control and anxiety in college students. Psychological Reports, 40, 1236-1238. doi:10.2466/ pr0.1977.40.3c.1236

Domino, G., \& Domino, M. (2006). Psychological testing: An introduction (2nd ed.). New York, NY: Cambridge University Press.

Essau, C., Sasagawa, S., \& Frick, P. (2006). Callous-unemotional traits in community sample of adolescents. Assessment, 13, 454-469. doi: 10.1177/1073191106287354

Farrington, D. P. (2005). The importance of child and adolescent psychopathy. Journal of Abnormal Child Psychology, 33, 489-497. doi:10.1007/s10802-005-5729-8

Feshbach, N. D., \& Feshbach, S. (1969). The relationship between empathy and aggression in two age groups. Developmental Psychology, 1(2), 102-107. doi:10.1037/h0027016

Frick, P., Barry, C., \& Bodin, S. (2000). Applying the concept of psychopathy to children: Implications for the assessment of antisocial youth. In C. Gacono (Ed.), The clinical and forensic assessment of psychopathy: A practitioner's guide (pp. 1-24). Mahwah, NJ: Lawrence Erlbaum.

Frick, P., \& Hare, R. (2001). The antisocial process screening device (APSD): Technical manual. Toronto, Ontario: Multi-Health System.

Frick, P., O'Brien, B., Wootton, J., \& McBurnett, K. (1994). Psychopathy and conduct problems in children. Journal of Abnormal Psychology, 103, 700-707. doi: 10.1037//0021-843X.103.4.700

Frick, P. J., Ray, J. V., Thornton, L. C., \& Kahn, R. E. (2013). Can callous-unemotional traits enhance the understanding, diagnosis, and treatment of serious conduct problems in children and adolescents? A comprehensive review. Psychological Bulletin, 140(1), 1-57. doi:10.1037/ a0033076

Geng, Y., Xia, D., \& Qin, B. (2012). The Basic Empathy Scale: A Chinese validation of a measure of empathy in adolescents. Child Psychiatry \& Human Development, 43, 499-510. doi:10.1007/ s10578-011-0278-6

Gordon, G., Dalton, S., Kolbert, J. B., Kanyongo, G. Y., \& Crothers, L. M. (2014). Proactive and reactive aggression and cognitive and affective empathy among students in middle school. International Journal of School and Cognitive Psychology, 1, 1-6.

Grynberg, D., Luminet, O., Corneille, O., Grèzes, J., \& Berthoz, S. (2010). Alexithymia in the interpersonal domain: A general deficit of empathy? Personality and Individual Differences, 49, 845-850. doi:10.1016/j.paid.2010.07.013 
Hambleton, R., Merenda, P., \& Spielberger, C. (2005). Adapting educational and psychological tests for cross-cultural assessment. Mahwah, NJ: Lawrence Erlbaum Associates.

Hare, R. (2003). The Hare psychopathy checklist-Revised: Technical manual (2nd ed.). Toronto, Ontario: Multi-Health Systems.

Hare, R. D., \& Neumann, C. S. (2010). Psychopathy: Assessment and forensic implications. In L. AQ24 Malatesti \& J. McMillan (Eds.), Responsibility and psychopathy: Interfacing law, psychiatry and philosophy (pp. 93-123). Oxford: Oxford University Press.

Hoffman, M. L. (2008). Empathy and prosocial behavior. Handbook of emotions, 3, 440-455.

Hogan, R. (1969). Development of an empathy scale. Journal of Consulting and Clinical Psychology, 33, 307-316. doi:10.1037/h0027580

Jolliffe, D., \& Farrington, D. P. (2004). Empathy and offending: A systematic review and metaanalysis. Aggression and Violent Behavior, 9, 441-476. doi:10.1016/j.avb.2003.03.001

Jolliffe, D., \& Farrington, D. (2006). Development and validation of the Basic Empathy Scale. Journal of Adolescence, 29, 589-611. doi:10.1016/j.adolescence.2005.08.010

Jolliffe, D., \& Farrington, D. P. (2007). Examining the relationship between low empathy and selfreported offending. Legal and Criminological Psychology, 12, 265-286. doi:10.1348/ $135532506 \mathrm{X} 147413$

Kaplan, R., \& Saccuzzo, D. (2009). Psychological testing: Principles, applications, and issues. Belmont, CA: Wadsworth, Cengage Learning.

Kimonis, E. R., Frick, P. J., Fazekas, H., \& Loney, B. R. (2006). Psychopathy, aggression, and the processing of emotional stimuli in non-referred girls and boys. Behavioral Sciences \& the Law, 24(1), 21-37. doi:10.1002/bsl.668

Kimonis, E. R., Frick, P. J., Skeem, J. L., Marsee, M. A., Cruise, K., Munoz, L. C., ... Morris, A. S. (2008). Assessing callous-unemotional traits in adolescent offenders: Validation of the Inventory of callous-unemotional traits. International Journal of Law and Psychiatry, 31, 241-252. doi:10.1016/j.ijlp.2008.04.002

La Greca, A., \& Lopez, N. (1998). Social anxiety among adolescents: Linkages with peer relations and friendships. Journal of Abnormal Child Psychology, 26(2), 83-94. doi:10.1023/ A: 1022684520514

Leech, N., Barrett, K., \& Morgan, G. (2015). IBM SPSS for intermediate statistics: Use and interpretation (5th ed.). New York, NY: Routledge.

Maroco, J. (2014). Análise de Equações Estruturais: Fundamentos teóricos, software \& aplicações [Structural equations analysis: Theoretical foundations, software and applications]. Pero Pinheiro: Report Number, Ltd.

Mehrabian, A. (1996). Manual for the balanced emotional empathy scale (BEES). Monterey, CA: Albert Mehrabian.

Mehrabian, A., \& Epstein, N. (1972). A measure of emotional empathy. Journal of Personality, 40, 525-543. doi:10.1111/j.1467-6494.1972.tb00078.x

Miller, J. D., \& Lynam, D. R. (2003). Psychopathy and the five-factor model of personality: A replication and extension. Journal of Personality Assessment, 81, 168-178. doi:10.1207/ S15327752JPA8102_08

Muñoz, L., \& Frick, $\overline{\text { P. }}$ (2007). The reliability, stability, and predictive utility of the self-report version of the antisocial process screening device. Scandinavian Journal of Psychology, 48, 299-312.

Muñoz, L. C. (2009). Callous-unemotional traits are related to combined deficits in recognizing afraid faces and body poses. Journal of the American Academy of Child \& Adolescent Psychiatry, 48, 554-562. doi:10.1097/CHI.0b013e31819c2419

Muñoz, L. C., Qualter, P., \& Padgett, G. (2011). Empathy and bullying: Exploring the influence of callous-unemotional traits. Child Psychiatry \& Human Development, 42, 183-196. doi:10.1007/ s10578-010-0206-1

Nguyen, A. B., Clark, T. T., \& Belgrave, F. Z. (2011). Empathy and drug use behaviors among African-American adolescents. Journal of Drug Education, 41, 289-308. doi:10.2190/DE.41.3.d

Pardini, D. A., Lochman, J. E., \& Frick, P. J. (2003). Callous/unemotional traits and socialcognitive processes in adjudicated youths. Journal of the American Academy of Child \& Adolescent Psychiatry, 42, 364-371. doi:10.1097/00004583-200303000-00018

Pechorro, P., Maroco, J., Poiares, C., \& Vieira, R. (2013). Validation of the Portuguese version of the antisocial process screening device self-report with a focus on delinquent behavior and 
behavior problems. International Journal of Offender Therapy and Comparative Criminology, 57 (1), 112-126. doi:10.1177/0306624X11427174

Pechorro, P., Ray, J., Barroso, R., Maroco, J., \& Gonçalves, R. (in press). Validation of the AQ26 inventory of callous-unemotional traits among a Portuguese sample of detained juvenile offenders. International Journal of Offender Therapy and Comparative Criminology. doi:10. 1177/0306624X14551256

Pechorro, P., Ray, J., Raine, A., Maroco, J., \& Gonçalves, R. (2015). The Reactive-Proactive AQ2‡ Aggression Questionnaire: Validation among a Portuguese sample of juvenile delinquents. Manuscript submitted for publication.

Pechorro, P., Silva, I., Maroco, J., \& Gonçalves, R. (2014). Propriedades psicométricas da Escala de AQ2§. Ansiedade Social para Adolescentes em jovens institucionalizados [Psychometric properties of the Social Anxiety Scale for Adolescents among institutionalized youths]. Psicologia, Saúde e Doenças. 15, 586-596. doi:10.15309/14psd150303

Raine, A., Dodge, K., Loeber, R., Gatzke-Kopp, L., Lynam, D., Reynolds, C., ... Liu, J. (2006). The reactive-proactive aggression questionnaire: Differential correlates of reactive and proactive aggression in adolescent boys. Aggressive Behavior, 32, 159-171. doi:10.1002/ab.20115

Salas-Wright, C., Olate, R., \& Vaughn, M. (2012). Assessing empathy in Salvadoran high-risk and gang-involved adolescents and young adults: A Spanish validation of the Basic Empathy Scale. International Journal of Offender Therapy and Comparative Criminology, 57, 1393-1416. doi:10.1177/0306624X12455170

Sevecke, K., \& Kosson, D. (2010). Relationships of child and adolescent psychopathy to other forms of psychopathology. In R. Salekin \& D. Lynam (Eds.), Handbook of child and adolescent psychopathy (pp. 284-314). New York, NY: The Guilford Press.

Tibi-Elhanany, Y., \& Shamay-Tsoory, S. (2011). Social cognition in social anxiety: First evidence for increased empathic abilities. Israel Journal of Psychiatry and Related Sciences, 48(2), 98-106.

Topçu, C., \& Erdur-Baker, Ö. (2012). Affective and cognitive empathy as mediators of gender differences in cyber and traditional bullying. School Psychology International, 33, 550-561. doi: $10.1177 / 0143034312446882$

Vachon, D., Lynam, D., \& Johnson, J. (2014). The (non)relation between empathy and aggression: AQ31 Surprising results from a meta-analysis. Psychological Bulletin, 140, 751-773. doi:10.1037/ a0035236

van der Helm, G. H. P., Stams, G. J. J. M., van der Stel, J. C., van Langen, M. A. M., \& van der Laan, P. H. (2012). Group climate and empathy in a sample of incarcerated boys. International Journal of Offender Therapy and Comparative Criminology, 56, 1149-1160. doi:10.1177/ 0306624X11421649

van Langen, M. A. M., Wissink, I. B., van Vugt, E. S., van der Stouwe, T., \& Stams, G. J. J. M. (2014). The relation between empathy and offending: A meta-analysis. Aggression and Violent Behavior, 19, 179-189. doi:10.1016/j.avb.2014.02.003 